This was a retrospective study and the results are, therefore, dependent on the quality of information in the notes studied. There may have been recall bias of atopic and family history in known asthmatics, but this would seem less likely in the cases only subsequently diagnosed as asthmatic. The numbers were also limited, by ethical constraints, to those children followed-up within the hospital. It is possible that these were more severely ill, but no significant differences were demonstrated between those followed-up in hospital or at home. A further six-year follow-up of all 131 potential cases is under way to overcome this, and also to differentiate between BHR, which declines with time, and asthma. On the basis of these preliminary results, however, it seems reasonable to suggest that children admitted with pneumonia are followed-up about six weeks later with a high index of suspicion for asthma, particularly if there is a family history of asthma and a personal history of atopy. In this study a quarter of the original cohort were left to follow-up in general practice, and it might be expected that another two or three cases of asthma would be diagnosed among them.

\section{CONCLUSION}

This study suggests that careful follow-up of children after an episode of pneumonia may be useful in determining previously undiagnosed cases of asthma. A prospective study may be useful.

\section{Acknowledgements}

I wish to thank Dr Alex Ferguson for his inspiration and support for this work, and my wife Karen for her tolerance during it.

\section{Conflict of interest: None}

Funding: None.

\section{References}

1. Turner-Warwick M. Nocturnal asthma: a study in general practice. J R Coll Gen Pract 1989; 39: 239-43.

2. Levy M, Bell M. General practice audit of asthma in childhood. BMJ 1984; 289:1115-6.

3. Jones A, Sykes A. The effect of symptom presentation on delay in asthma diagnosis in children in a general practice. Respir Med 1990; 84: $139-42$

4. Speight A N P, Lee D A, Hey E N. Underdiagnosis and undertreatment of asthma in childhood. BMJ 1983; 286: 1253-6.

5. Levy M and Hilton S. Asthma in Practice. Exeter, Royal College of General Practitioners, 1992 (2nd ed); 17.

6. Dean A G, Dean J A, Burton A H et al. Epi-Info, Version 5: a word processing, database, and statistics program for epidemiology on microcomputers. Stone Mountain, US, USD Inc, 1990.

7. Springer C, Avital A, Noviski N et al. Role of infection in middle lobe syndrome in asthma. Arch Dis Child 1992; 67: 592-4.

8. Hopp R J, Townley R G, Biven R E et al. The presence of airway reactivity before the onset of asthma. Am Rev Respir Dis 1990; 141: $2-8$

9. Strachan D P, Butland B K, Anderson H R. Incidence and prognosis of asthma and wheezing illness from early childhood to age 33 in a national British cohort. BMJ 1996; 312: 1195-9.

10. Gold D R, Tager I B, Weiss S T et al. Acute lower respiratory illness in childhood as a predictor of lung function and chronic respiratory symptoms. Am Rev Respir Dis 1989; 140: 877-84.

11. Korppi M, Kuikka L, Reijonen T et al. Bronchial asthma and hyperreactivity after early childhood bronchiolitis or pneumonia. Arch Pediatr Adolesc Med 1994; 148: 1079-84.

12. Mok JY Q and Simpson H. Outcome for acute bronchitis, bronchiolitis and pneumonia in infancy. Arch Dis Child 1984; 59: 306-9.

13. Camilli A E, Holberg C J, Wright A L et al. Parental childhood respiratory illness and respiratory illness in their infants. Pediatric Pulmonology 1993; 16: 275-80

\title{
How do patients operate self-management plans?
}

\author{
M E Hyland
}

ABSTRACT

Objective: To examine the extent to which patients are empowered by their doctor or nurse to adjust their asthma medication dose using self-management plans.

Method: $\quad$ A small survey was undertaken among 114 asthma patients (from 14 practices) on regular maintenance inhaled steroid therapy. Patients were asked to complete an anonymous questionnaire about the instructions they had been given and their use of their steroid inhaler.

Results: $\quad$ Seventy seven per cent of the 114 asthmatics in the survey would increase their 'brown' inhaler if their symptoms got worse and $40 \%$ would reduce their 'brown' inhaler if they had no symptoms. On the whole, the patients' description of their selfmanagement plans reflected the reported advice given by the doctor/nurse, although there was evidence of some intentional non-compliance. Most notably, $17 \%$ reported that they would stop using their 'brown' inhaler if they had no symptoms.
Conclusion: Younger patients were empowered to manage their asthma more than older patients. Patients are more likely to be advised to step up their prophylactic therapy during uncontrolled episodes, rather than to step down when their asthma comes under control. Although the majority of patients reported that they followed the instructions they were given, a significant minority reported deliberate non-compliance with the use of prophylactic treatment.

\section{INTRODUCTION}

Self-management plans (SMPs) have been an accepted part of asthma management for many years, ${ }^{1}$ and the principle that 'patients or parents should be enabled to manage their own treatment rather than be required to consult the doctor before making changes' is integral to the British Thoracic Society guidelines for asthma management. $^{2-4}$

However, SMPs can vary in the degree of control given to the patient. Consider the following three approaches to management:

\section{Michael Hyland \\ Professor of Health Psychology}

Correspondence to: Department of Psychology, University of Plymouth, Plymouth PL4 8AA.

Asthma in Gen Pract 1997; 5(1): 11-13. 
Table 1: Relationship between reported doctor's instructions and patient's behaviour. Table shows frequency in various categories of response and significance

\begin{tabular}{|c|c|c|c|c|c|}
\hline & No & $\begin{array}{l}\text { Not } \\
\text { sure }\end{array}$ & Yes & $\begin{array}{l}\text { Practice } \\
\text { effect }\end{array}$ & $\begin{array}{l}\text { Age } \\
\text { effect }\end{array}$ \\
\hline $\begin{array}{l}\text { 1. Has the doctor or nurse } \\
\text { suggested that you should } \\
\text { increase the number of puffs } \\
\text { of your brown inhaler when } \\
\text { your symptoms get worse? }\end{array}$ & 21.9 & 4.4 & 73.7 & 0.002 & 0.040 \\
\hline $\begin{array}{l}\text { 2. Has the doctor or nurse } \\
\text { suggested that you could } \\
\text { reduce the number of puffs } \\
\text { of your brown inhaler when } \\
\text { your symptoms get better? }\end{array}$ & 47.4 & 6.1 & 46.5 & $<0.001$ & $<0.001$ \\
\hline $\begin{array}{l}\text { 3. Do you take your brown } \\
\text { inhaler less than you have } \\
\text { been told, on purpose? }\end{array}$ & 85.8 & 1.8 & 12.4 & & \\
\hline $\begin{array}{l}\text { 4. Do you ever forget to take } \\
\text { your brown inhaler? }\end{array}$ & 40.4 & 0.9 & 58.8 & 0.020 & 0.030 \\
\hline $\begin{array}{l}\text { 5. Would you increase your } \\
\text { brown inhaler if your } \\
\text { symptoms got worse? }\end{array}$ & 16.7 & 6.1 & 77.2 & & \\
\hline $\begin{array}{l}\text { 6. Would you reduce your } \\
\text { brown inhaler if you had } \\
\text { no symptoms? }\end{array}$ & 48.7 & 10.6 & 40.7 & 0.006 & \\
\hline $\begin{array}{l}\text { 7. Would you stop your } \\
\text { brown inhaler when you } \\
\text { had no symptoms? }\end{array}$ & 66.7 & 15.8 & 17.5 & 0.005 & \\
\hline $\begin{array}{l}\text { 8. Does your peak flow } \\
\text { reading influence whether } \\
\text { or not you take your brown } \\
\text { inhaler? }\end{array}$ & 57.0 & 16.7 & 26.3 & & \\
\hline
\end{tabular}

i) the patient is put on a sufficiently high dose of regular inhaled steroid so that exacerbations are extremely rare, and consequently there is no need for the patient to increase steroid dose. When exacerbations occur specialist intervention is required.

ii) the patient is placed on a dose of regular inhaled steroid where certain triggers (e.g. developing a cold) lead to the need for increased steroid dose.

iii) the patient is placed on a dose of inhaled steroid for general regular use, but advised to increase the dose when symptoms deteriorate and to reduce when symptoms get better.

Patients vary in their competence and also in the extent to which they want to control their environment. ${ }^{5}$ There is some evidence from other fields of medicine that people with a high desire for control gain more benefit from interventions providing control than those with a low desire for control. ${ }^{6}$ Thus, from a psychological perspective, it may be appropriate to individualise the degree of control provided by the SMP to the characteristics of the patient. In a clinical setting, variation in SMPs may reflect differences in the psychological characteristics of the patients, or the degree to which the health care professional believes that patients should be empowered. This survey examines patient empowerment in terms of patient reports about dose change decisions.

\section{METHOD}

Practice nurses from 14 practices in the Plymouth area with nurse-run asthma clinics agreed to distribute a questionnaire and an information/consent letter to the next 15 to 20 patients who attended the clinic and who were on regular inhaled steroids (any dose). Patients completed the questionnaire at home and posted it anonymously, in a pre-paid envelope, to the University of Plymouth. Patients were informed that the questionnaires were precoded to identify their practice. Patients indicated their age by ticking one of four age ranges. The items in the questionnaire are shown in Table 1 (two introductory items are not shown). The effect of practice and age on the patients' responses were tested using the Chi square test.

\section{RESUlts}

One hundred and fourteen patients returned questionnaires: four were under 16 years old, 20 were 16-25 years, 26 were 26-40 years, 56 were above 41 years and eight did not indicate their age. There was significant variation between practices in the ages of patients recruited $(\mathrm{p}=0.03)$, see Table 1 . The number of patients per practice completing the questionnaire varied between one and 17 , with a median of nine patients. The frequency of response to the questions and significant differences by practice and age are shown in Table 1.

Overall, $74 \%$ of patients reported that they had been instructed to increase the dose of inhaled steroids in response to symptom deterioration (Question 1), although there were variations between practices. At one extreme, all $17(100 \%)$ patients who attended a particular practice responded 'yes' to Question 1; at the other, only one out of six (17\%) patients from another practice responded 'yes'. The response to Question 1 also depended on the patient's age. Patients under 41 years were more likely to indicate that they had been told to increase their prophylactic medicine if their symptoms worsened: only $16 \%$ of patients under 41 failed to say 'yes', compared with $34 \%$ of those over 41 years.

Patients reported that fewer doctors recommended that they should reduce the dose of inhaled steroids when symptoms improved (Question 2, Table 1) compared with the number recommending stepping up treatment in response to deterioration (about 50\%). The proportion of patients reporting that they had been told to reduce their steroid dose when their symptoms were under control also varied between practices. At one practice, 12 out of $15(80 \%)$ said 'yes' to Question 2 , whereas at another only three out of $15(20 \%)$ responded 'yes'. Patients over 41 years were less likely to respond that they had been told to step down the dose.

For the majority of patients, their reported operation of their SMP mirrored the instructions that they reported receiving from the doctor/nurse (see Table 2 ).

However, in a minority of cases there was a discrepancy between reported instruction and behaviour. Seventeen patients would not reduce their 
prophylactic medicine despite being told they could, and 12 reported that they would reduce their prophylactic medicine despite not being told to do so.

More patients who reported that the doctor had told them to reduce their steroid dose if their symptoms improved said they would stop treatment in such circumstances than among the patients who had not been told to reduce the dose. Nevertheless, about a third of patients who said they would stop using their steroid inhaler if their asthma improved had not been given instructions about reducing the dose.

Three other questions produced interesting data. First, more than half the patients reported that they sometimes forgot to take their prophylactic medicine; patients under 41 years old were more likely to forget. Second, more than half of the patients reported that the use of their prophylactic inhaler was not influenced by their peak flow reading and a surprising $17 \%$ were not sure about this. Third, $12 \%$ of patients reported intentional under-use of their prophylactic medicine compared to the instructions they had been given.

\section{Discussion}

These data show that there is significant variation in the extent to which patients are empowered or empower themselves in operating their SMPs. Some patients do not change their dose of inhaled steroid; others increase the dose when their symptoms worsen; a further group adjust the dose in line with a worsening or improvement in symptoms.

Variation in asthma SMPs is consistent with an individualised approach to empowerment, and there is some evidence that individualisation was responsible for some of the observed variation between plans. For example, younger patients were, on average, empowered more than older patients which would be consistent with a view (a reasonable view, although without supporting evidence) that older asthmatic patients prefer less control or need simpler instructions. However, there were also differences between practices in the extent to which patients were empowered to change their medication, implying different practice policies with regard to empowering patients. This conclusion should be treated with considerable caution because the patients were not randomly selected and may not be typical of asthma patients in general. In particular, the patients' age distribution was different between practices. The patients could have been selected on a different basis at each practice (recruitment rates were substantially different) and hence these data may not be representative.

Although the majority of patients operate their SMPs at the level of control that they are given, some patients prefer to exert more control than they have been given, and others less, i.e. they operate using a simpler plan than the one they report that they have been advised to follow. Interestingly, these data indicate that similar proportions of patients exert more and less control.

Objective studies of patient compliance with prophylactic medicines show that it is common for patients to under-use their prescribed treatment, but some over-use their medication.?
Table 2: Percentage responses to items in questionnaire and whether there are significant effects by practice and by patient's age

\begin{tabular}{|c|c|c|c|c|c|}
\hline $\begin{array}{l}\text { Doctor has said } \\
\text { increase }\end{array}$ & $\begin{array}{l}\text { No } \\
\text { Not sure } \\
\text { Yes }\end{array}$ & $\begin{array}{r}\mathrm{Pa} \\
\mathrm{No} \\
14 \\
1 \\
4\end{array}$ & $\begin{array}{l}\text { nt would in } \\
\text { Not sure } \\
5 \\
2 \\
0\end{array}$ & $\begin{array}{l}\text { crease } \\
\text { Yes } \\
6 \\
2 \\
80\end{array}$ & $<0.0001$ \\
\hline $\begin{array}{l}\text { Doctor has said } \\
\text { reduce }\end{array}$ & $\begin{array}{l}\text { No } \\
\text { Not sure } \\
\text { Yes }\end{array}$ & $\begin{aligned} \mathrm{Pa} & \\
\mathrm{No} & \\
36 & \\
2 & \\
17 & \end{aligned}$ & $\begin{array}{l}\text { nt would re } \\
\text { Not sure } \\
5 \\
1 \\
6\end{array}$ & $\begin{array}{l}\text { duce } \\
\text { Yes } \\
12 \\
4 \\
30\end{array}$ & 0.003 \\
\hline $\begin{array}{l}\text { Doctor has said } \\
\text { reduce }\end{array}$ & $\begin{array}{l}\text { No } \\
\text { Not sure } \\
\text { Yes }\end{array}$ & \multicolumn{3}{|c|}{\begin{tabular}{rcc}
\multicolumn{3}{l}{ Patient would stop } \\
No & Not sure & Yes \\
42 & 6 & 6 \\
3 & 2 & 2 \\
31 & 2 & 12
\end{tabular}} & NS \\
\hline
\end{tabular}

Although limited in its scope, this study shows that intentional non-compliance takes a variety of forms. Intentional non-compliance is not simply a matter of patients exerting more control, in the form of taking less medication, than that provided by the health professional. Whether under-use is more likely in patients given less control over their own treatment, because they empower themselves more than they have been allowed, is as yet unknown. The individualisation of asthma SMPs to suit the psychological characteristics of the patient is a topic requiring further investigation.

\section{CONCLuSION}

Younger patients were empowered to manage their asthma more than older patients. Patients are more likely to be advised by the nurses (presumably according to practice protocols) to step up their prophylactic therapy during uncontrolled episodes, rather than to step down when their asthma comes under control. Although the majority of patients in this study reported that they followed the instructions they were given, a significant minority reported deliberate non-compliance with the use of prophylactic treatment.

\section{Acknowledgements}

I would like to thank J LeM House, J Larbalasteier and M Coyte for co-ordinating the data collection and $\mathrm{S}$ Sodergren for the analysis.

\section{References}

1. Klingelhofter E L, Gershwin M E. Asthma self-management programs - premises, not promises. J of Asthma 1988; 25: 89 101.

2. British Thoracic Society, Royal College of Physicians of London, King's Fund Centre et al. Guidelines for the management of asthma in adults 1: Chronic persistent asthma. BMJ 1990; 301: 651-3.

3. The British Thoracic Society, British Paediatric Association,

Royal College of Physicians of London et al. Guidelines for the management of asthma. Thorax 1993; 48: S1-24.

4. The British Thoracic Society, The National Asthma

Campaign, The Royal College of Physicians of London et al.

British guidelines on asthma management: 1995 review and

position statement. Thorax 1997; 52: S1-24.

5. Burger J M, Cooper H M. The desirability of control.

Motivation and Emotion 1979; 3: 381-93.

6. Logan H K, Baron R S, Keeley K et al. Desired control and

felt control as mediators of stress in a dental setting. Health

Psychology 1991; 10: 352-9.

7. Chmelik F, Doughty A. Objective measurements of

compliance in asthma treatment. Ann Allergy 1994; 73: 527-32. 